Kleiboer, A.M., Kuijer, R.G., Hox, J.J., Schreurs, K.M.G., Bensing, J. Receiving and providing support in couples dealing with multiple sclerosis: a diary study using an equity perspective. Personal Relationships: 2006, 13(4), 485-501

\begin{tabular}{|l|l|}
\hline $\begin{array}{l}\text { Postprint } \\
\text { Version }\end{array}$ & 1.0 \\
\hline $\begin{array}{l}\text { Journal website } \\
\text { Pubmed link }\end{array}$ & http://www.blackwell-synergy.com/doi/abs/10.1111/j.1475-6811.2006.00131.x \\
\hline DOI & \\
\hline
\end{tabular}

This is a NIVEL certified Post Print, more info at http://www.nivel.eu

\title{
Receiving and providing support in couples dealing with multiple sclerosis: A diary study using an equity perspective
}

\author{
ANNET M. KLEIBOER, ${ }^{\mathrm{A}}$ ROELINE G. KUIJER, ${ }^{\mathrm{B}}$ JOOP J. HOX, ${ }^{\mathrm{A}}$ KARLEIN M. G. \\ SCHREURS, ${ }^{\mathrm{C}}$ AND JOZIEN M. BENSING ${ }^{\mathrm{A}, \mathrm{D}}$ \\ aUtrecht University, Utrecht, the Netherlands; \\ bUniversity of Canterbury, Christchurch, New Zealand; \\ cRehabilitation Centre 'Het Roessingh', Enschede, the Netherlands; \\ dNivel, Netherlands Institute for Health Services Research, Utrecht, the Netherlands
}

\begin{abstract}
This study examined the effects of daily support exchanges in couples facing multiple sclerosis (MS). Two issues were examined: the imbalance between received and provided support, and the extent to which reciprocal exchanges of received and provided support are associated with end-of-day well-being (positive and negative mood and selfesteem).

Guided by equity theory, we expected that one-sided support provision or receipt would be harmful for well-being for both patients and partners. We argued that these negative outcomes could be offset by reciprocating support, that is, when both partners receive and provide support. Sixty-one patients and their partners filled out questionnaires on demographics and disease-related characteristics and subsequently completed computerized daily diaries for 14 days. At the end of each day, both partners completed diaries on end-of-day mood, self-esteem, received and provided emotional and instrumental support, and several control variables (daily hassles and MS-related symptoms for patients). Reciprocity in instrumental support transactions was associated with higher levels of self-esteem among both patients and partners. However, the other results all showed independent effects of support received and provided. Patients' well-being was related to providing emotional support and instrumental support, whereas partners' well-being was related to receiving emotional support from patients.
\end{abstract}

Many studies have described the beneficial effects of spousal supportive behaviors on wellbeing in general (e.g.,Burman\&Margolin, 1992), as well as on adjustment to chronic illness (e.g., Cutrona, 1996). In the literature, a conceptual distinction has been made between the 
perceived availability of support and actual received support or enacted support (DunkelSchetter \& Bennett, 1990). It is now generally acknowledged that the global perception that support is available when it is needed is related to greater psychological and physical wellbeing (e.g., Lindorff, 2000; Sarason, Sarason, \& Gurung, 2001). However, results are less consistent when the effects of actual received support are studied. Some studies have documented positive effects (e.g., Manne \& Zautra, 1989; Riemsma et al., 2000), whereas others have shown neutral effects (e.g., Bolger, Foster, Vinokur, \& Ng, 1996) or even negative effects (e.g., Bolger, Zuckerman, \& Kessler, 2000; Newsom \& Schulz, 1998). One explanation that has been offered for these negative findings is that the receipt of social support and help may only contribute to well-being when it is given within a relationship that is characterized by reciprocal patterns of exchange (Antonucci \& Jackson, 1990; Buunk \& Schaufeli, 1999). A recent study by Gleason, Iida, Bolger, and Shrout (2003), for example, showed that receiving support had a negative impact on mood only when the recipient failed to provide support in return. Moreover, the fact that providing support may be rewarding in itself and thus may have a positive impact on well-being has often been overlooked (Liang, Krause, \& Bennett, 2001).

The present study aimed to further our understanding of the association between reciprocal exchanges of social support and well-being among couples in which one partner is diagnosed with a chronic illness (i.e., multiple sclerosis [MS]). An important feature of the study was that both patients and partners were considered providers as well as receivers of social support. For the most part, social support research in the context of adaptation to illness is focused on the patient as the support receiver and the partner as the support provider, thereby neglecting the fact that patients may also provide support and thus partners may also receive support from their ill partners.

\section{Providing and receiving support in the context of illness}

MS is a chronic and often disabling disease of the central nervous system, most commonly diagnosed in young adulthood (i.e., between ages 20 and 40). The prevalence among women is about two to three times higher than in men (Zwanikken, 1997). The etiology of the illness is still unknown and the onset of the disease may be gradual or acute. Relapses may be followed by periods of remission, or there may be a progressive decline in health (Lublin \& Reingold, 1996). Depending on the location of the lesions in the central nervous system, the illness can produce a wide variety of symptoms including loss of function, debilitating fatigue, visual problems, and emotional changes (e.g., Mohr \& Dick, 1998). The severity of the disease, the unpredictability of its course, and the moderate effectiveness of medical treatment make MS a very difficult disease to adjust to, not only for the patient but also for the partner. In order to deal with the MS, patients may need increasing amounts of both instrumental help and emotional support from their partners. However, the healthy partner is also likely to experience distress (Knight, Devereux, \& Godfrey, 1997; Pakenham, 1998) and may also need support from his or her partner.

Several researchers have suggested that social support exchanges may become more unidirectional when one partner has a chronic illness (Cutrona, 1996; Thompson \& Pitts, 1992), that is, patients may receive more support and help from their partners and provide less in return. Research among couples coping with cancer (e.g., Kuijer, Buunk, \& Ybema, 2001) and partners of cardiac patients (Thompson, Medvene, \& Freedman, 1995) showed that when patients and partners were asked to provide a global appraisal of the balance of give and take in their relationships, patients generally felt that their partners were doing more for them than the other way around, whereas partners generally felt that the relationship was balanced in terms of give and take. In the present study, we did not ask participants to make global judgments of support exchanges; rather, we asked them to report the extent to which they received and provided emotional and instrumental support from and to their partners on 
Kleiboer, A.M., Kuijer, R.G., Hox, J.J., Schreurs, K.M.G., Bensing, J. Receiving and providing support in couples dealing with multiple sclerosis: a diary study using an equity perspective. Personal Relationships: 2006, 13(4), 485-501

14 consecutive days. Due to the physical disability associated with the MS, it is likely that patients receive more instrumental help than they provide.

Thus, we expected that compared to their partners, patients would report receiving more and providing less instrumental support. We hypothesized that the imbalance between providing and receiving emotional support would be less pronounced since it would be easier for patients to reciprocate emotional support.

\section{Social support exchanges and well-being}

Although spousal support is believed to be a critical resource for dealing with chronic illness (Cutrona, 1996), there is now accumulating evidence that spousal support does not always have positive outcomes for patients (e.g., Bolger et al., 1996; Newsom \& Schulz, 1998). Several researchers have suggested that support and help from others often contains a mixture of enhancing and threatening elements.

On the one hand, support may communicate that one is loved and cared for. On the other hand, it may signal that one has failed, is dependent, or is incompetent (Fisher, Nadler, \& Whitcher-Alagna, 1982; Gleason et al., 2003; Liang et al., 2001). In couples dealing with a chronic illness, this may apply to both partners, although these feelings may be more pronounced among patients. In addition, for patients, support may emphasize their status as an 'impaired person"' (DiMatteo \& Hays, 1981). As a result, social support may undermine the recipient's self-esteem, well-being, and feelings of autonomy. Another explanation for the negative effects of social support is that it might make the recipient feel indebted to his or her partner (Walster, Walster, \& Berscheid, 1978). This may result in feelings of guilt. One way in which the adverse effects of receiving support may be offset is by providing support in return. Providing support allows one to display positive attributes such as concern, love, and commitment (Rusbult \& Van Lange, 1996); it may draw attention away from one's own problems and communicates independence (Gleason et al., 2003). The latter may be especially important for individuals with a chronic disease as they are often placed in a position of dependence. Although few studies have paid attention to the impact of giving support, research suggests that, in general, it is associated with greater well-being (Brown, Nesse, Vinokur, \& Smith, 2003; Silverstein, Chen, \& Heller, 1996). Helping someone in need may be a fulfilling experience and may boost self-esteem. In an experiment, Williamson and Clark (1989) showed that individuals who thought they would be helping someone with whom they would like to have a communal relationship experienced increased positive mood and self-esteem. Research that pays attention to the positive effects of caregiving suggests that caregiving may improve people's sense of self-worth and confidence in meeting challenges (Nijboer et al., 1998; Ybema, Kuijer, Hagedoorn, \& Buunk, 2002).

However, there may also be considerable costs to providing ongoing support and help to others. In fact, in the literature on caregiving, the positive aspects have received far less attention than the negative aspects (Martire \& Schulz, 2001). Ample research has shown that the provision of ongoing care and support to an individual with a chronic illness is often a stressful experience and partners may become overburdened by the amount of support and help that needs to be provided (Martire \& Schulz). Several studies have shown that support received from the care recipient may buffer the negative consequences of caregiving. For example, Wright and Aquilino (1998) found that reciprocity of emotional support between caregiving wives and husbands who received care was linked to lower levels of burden among these wives.

In sum, we expected that reciprocity in receiving and providing support would be important for patients as well as their partners.

Receiving support without providing support in return may have negative consequences. The same is true for providing support without receiving any in return. Reciprocity in social exchanges has most often been studied from the perspective of equity theory (Walster et al., 1978). According to equity theory, feeling overbenefited as well as underbenefited is 
stressful. However, in the present study, we did not ask whether the participants felt equitably treated or not. We defined inequity as a situation in which a participant reported providing and receiving unequal amounts of support. This means that participants in inequitable situations may not have actually felt inequitably treated. Clark and Mills (1979) have suggested that depending on the nature of a relationship, different distributive justice norms apply. They argued that inequities do not tend to matter in intimate relationships because partners have a concern for the welfare of the other and respond to each other's needs without keeping track of contributions and rewards. Many studies have shown that perceptions of inequity are associated with more distress and lower relationship outcomes among healthy couples (e.g., Grote \& Clark, 2001; Sprecher, 2001) as well as among couples coping with illness (Kuijer et al., 2001; Thompson et al., 1995; Ybema, Kuijer, Buunk, DeJong, \& Sanderman, 2001; Ybema et al., 2002). However, these studies were generally based on global perceptions of inequity. To the best of our knowledge, the study by Gleason et al. (2003) is the only study that examined daily reciprocity in support transactions among healthy couples, thus far. They showed that the negative effects of inequitable emotional support transactions occurred during a short time span, that is, within a day. It is important to examine whether this is also the case among couples facing illness and whether this applies to the exchange of instrumental support.

\section{The current study}

The current study used a diary method to examine the exchange of emotional and instrumental support during an average 2-week period among couples in which one partner was diagnosed with MS. We distinguished between instrumental and emotional support because research has shown that different dimensions of social support may have different relations with well-being (Helgeson \& Cohen, 1996), even though they are highly correlated. The perceptions of each partner as a recipient and as a provider of support were considered. Note that when we say that support was received or provided, we always mean the recipient's perception of received support or the provider's perception of given support. Thus, patients and partners may not agree on the amount of support they reported receiving or providing.

As far as we know, this is the first study that examined support transactions with a diary method among couples dealing with illness.

This study examined two issues. First, we examined the balance of provided and received support. It was expected that patients would report receiving more instrumental support than they provided. The reverse was expected for partners. The imbalance was expected to be less pronounced for the exchange of emotional support. Second, and more central to our concerns, we investigated the relation between reciprocity of provision and receipt of emotional and instrumental support and daily mood and self-esteem among both patients and their partners. Although self-esteem is related to aspects of well-being, such as mood, it is conceptually different from these measures (Heatherton \& Polivy, 1991).

Self-esteem can be considered an evaluative component of the self that may vary as a function of daily events (Butler, Hokanson, \& Flynn, 1994). In the context of adjustment to chronic illness, self-esteem is a particularly relevant outcome measure because maintaining a sense of self-esteem is often mentioned as a challenge for patients (Bensing, Schreurs, De Ridder, \& Hulsman, 2002). Also for partners, self-esteem may be an important outcome of the support process (Nijboer et al., 1998). Further, one explanation for the importance of reciprocity of daily support exchanges that was offered by Gleason et al. (2003) was that it increases feelings of self-esteem. We hypothesized that, both for patients and partners, receiving and providing support would be beneficial only when the support was returned. In other words, we expected to find an interaction between received and provided support in such a way that for both patients and partners, a situation in which support was reciprocated would be related to higher levels of positive mood and self-esteem, and lower levels of negative mood. 
Kleiboer, A.M., Kuijer, R.G., Hox, J.J., Schreurs, K.M.G., Bensing, J. Receiving and providing support in couples dealing with multiple sclerosis: a diary study using an equity perspective. Personal Relationships: 2006, 13(4), 485-501

\section{METHOD}

\section{Participants}

Patients with MS and their partners were contacted through one MS Centre and the neurology department of one hospital in the Netherlands. Patients with MS registered in the patient files of these clinics received a letter with information about the study and a description of the inclusion criteria. As information on inclusion criteria were not available from the patient files (e.g., we do not know how many of these patients had a partner), we distributed letters to all 390 patients who were registered. This means that the number of couples who responded to the information letter cannot be used to calculate response rates. The selection criteria for participation were that (a) patients were diagnosed with MS, (b) patients were currently involved in a heterosexual relationship (with minimum relationship duration of 1 year), (c) patients were living together with their partner, and (d) both partners were willing to participate in the study. Couples were excluded if their ability to read or understand Dutch was insufficient, or when one or both partners suffered from serious psychiatric problems or medical problems other than MS.

A total of 70 couples, who met the inclusion criteria, responded to the information letter and signed informed consent. Of the 70 couples, a final sample of 61 couples completed all the materials. Reasons for drop out were MS-related health problems ( $\mathrm{n}=3$ ) and personal reasons $(n=3)$. Three couples did not specify a reason for drop out. Of the patients with MS, $87 \%(n=53)$ were women and $13 \%(n=8)$ men. Compared to the distribution of MS in the community (2-3:1; Zwanikken, 1997), female patients were slightly overrepresented in the present study. The mean age of patients was 47 years (range: $27-64$ years, $S D=8.5$ ), and on average, they had been diagnosed with MS 8 years previously (range: $1-33$ years, SD =6.0). Fifty-seven percent of the patients described their MS as having a relapse remitting course and $43 \%$ as having a progressive course. Thirty-one percent of the patients were employed (12\% full time and $20 \%$ part time), the other patients received a disability benefit (51\%), performed household duties (10\%), or were unemployed for other reasons (8\%). The partners of these patients were, on average, 49 years old (range: 29-69 years, SD =9.4). Most partners (80\%) were employed (61\% full time and 19\% part time), the other partners were retired (11\%) or were unemployed for other reasons (9\%).

Twenty-three percent of the patients and $27 \%$ of the partners had completed the lowest level of secondary (vocational) education only, $41 \%$ of the patients and $40 \%$ of the partners had completed middle to higher levels of secondary (vocational) education, and $36 \%$ of the patients and 33\% of the partners had a college degree or higher. The couples had been married (92\%) or cohabiting (8\%) for an average of 23 years (range: $2-41$ years, SD $=10.0$ ) and most couples had children (77\%).

\section{Procedure}

Prior to the diary part of the study, patients and partners completed background questionnaires on demographic and disease-related characteristics at home. Next, the first author or a research assistant visited all couples at home (1-4 weeks after sending the questionnaires) to provide additional information and instructions about the diary part of the study and to install an electronic diary on the couple's computer. Participants who did not own a computer were provided with a computer from the university. Computer software was developed especially for this study. The electronic diary was user friendly and easy to complete. Even participants who had little or no experience with computers were able to use the program after they were given clear instructions. Participants were instructed to complete the electronic diary every evening before going to bed for 2 weeks, starting the following day. Participants were explicitly asked not to exchange answers with their partners until both partners had completed that day's recordings. The diary was designed to be completed in 5min-10 min. Recordings were saved on a floppy disk each night and the participants did not have access to their reports after they were saved on the floppy disk. After 2 weeks, the couples returned the floppy disk containing each night's responses by mail. 
To verify compliance, the date and time of recordings were saved on the floppy disk. Participants were allowed to fill out the diary the next morning if they did not manage to do it at night. About $2.6 \%$ of the diaries were completed the next morning. If the diaries were completed after 2 p.m. on the next day, they were excluded from further analyses because they were considered to be too late and therefore unreliable. This was the case for $0.6 \%$ of the recordings. If the diaries were completed too early (before 2 p.m.), they were excluded from further analyses as well for the same reason. This was the case in $1.0 \%$ of the recordings.

Additionally, participants who completed less than 10 days during the 14-day period were excluded from further analyses.

For this reason, we excluded two healthy partners who completed 6 and 9 days of recordings, respectively. Across the 14-day period, participants reported an average of 13.1 days of recordings.

\section{Measures}

Received and provided support. Each evening, both patients and partners reported if and to what extent they had received and provided emotional and instrumental support on that day. Three items were used to measure received and provided emotional support, respectively. All answers were given on a 4 - point scale ( 0 =not at all, 3 =very much). The items were, "My partner gave me a compliment”/" I gave my partner a compliment," "My partner listened to me"/ "I listened to my partner," and "My partner showed affection towards me’"/ 'I showed affection towards my partner."' The items were averaged to form a scale for emotional support received and emotional support provided. Internal consistency of the scales was calculated based on the daily recordings; Cronbach's alpha was .75 for emotional support received and .70 for emotional support provided. One item was used to measure the receipt and provision of instrumental support, that is, "My partner gave me practical help"'/“'I gave my partner practical help.'” End-of-day mood was measured with the Positive and Negative Affect Schedule (PANAS; Watson, Clark, \& Tellegen, 1988).

The instrument consists of 10 positive and 10 negative adjectives that describe possible feelings and emotions. The items were scored on a 5-point scale ranging from (1) very slightly or not at all to (5) extremely. Scores on the positive items and the negative items were summed per day to form two scales, one scale for positive mood and one scale for negative mood. Both scales had a possible range from 10 to 50 indicating more positive or negative mood. Internal consistency of the scales was calculated based on the daily recordings; Cronbach's alpha was .88 for the positive scale and .86 for the negative scale. The PANAS has proven to be internally consistent and valid and when used with short-term instructions (right now or today), it is sensitive to fluctuations in mood (Watson et al., 1988). In this study, we used the following instructions: "Indicate to what extent you experience these feelings and emotions right now."' The correlation between positive and negative mood over days within individuals was close to zero $(\mathrm{r}=.09, \mathrm{p}<.01)$.

Self-esteem was assessed with a single item, asking to what extent participants valued themselves that day. The item was measured on a 7-point scale ranging from (1) not at all to (7) very much. According to Robins, Hendin, and Trzesniewski (2001), a single self-report item to assess self-esteem is adequate because the concept of self-esteem is (a) highly schematized for most individuals, (b) conceptually unidimensional in content, and (c) primarily reflects subjective experience. Further, in this study, the correlation between our measure for state self-esteem and the Rosenberg scale for trait self-esteem (Rosenberg, 1965) was .58 for patients and .61 for partners. Although state and trait self-esteem are conceptually different, these correlations provide some support for the validity of our instrument. Self-esteem correlated positively with positive mood $(r=.41, \mathrm{p}<.001)$ and negatively with negative mood $(\mathrm{r}=-.31, \mathrm{p}<.001)$ over days within individuals.

The number of daily hassles experienced each day was included as a control variable since hassles may influence the receipt of negative responses and emotional support. A checklist 
was used based on the Revised Hassle and Uplift Scale (DeLongis, Folkman, \& Lazarus, 1988). However, we considered the original 53-item scale too long to be used on a daily basis, so we shortened the scale by conjoining several items. One item referring to the occurrence of special incidents (e.g., accident) was added. This resulted in a 22-item scale that represented all the areas that were included in the original scale. Note that the uplifts part of the scale was not used in the present study.

Patients were asked each evening to indicate to what extent they had experienced MSrelated symptoms or complaints that day. The answer was given on a 10-point scale ranging from (1) no symptoms or complaints to (10) many symptoms and complaints.

\section{Analyses}

To compare the amount of received and provided emotional and instrumental support that patients and partners reported, we computed individual mean scores by aggregating the data across the 14-day period. Paired sample $t$ tests were used to test whether the differences between patients and partners were significant, and whether differences between the amount of received and provided support within patients and partners were significant. Additionally, to test the agreement between the patient's and partner's perceptions of the amount of support received and provided, we compared the amount of support that one partner reported receiving with the other partner's support provision. To adjust for multiple comparisons, the Bonferroni-Holm step-down procedure was used (Holm, 1979).

Multilevel regression modeling, as implemented in the program MLWin (Rasbash, Browne, Goldstein, \& Yang, 2000) was used to determine the relationship between the predictors and the dependent variables. Each model had three levels, a between-couple level (Level 3), a between-person level (Level 2), and a within-person level (Level 1). A between-couple level was included to take account of dependency within couples. A between-person level was included to take account of dependency within persons. The within-person level of the analyses allowed each individual's evening mood or self-esteem on a given day to be modeled as a function of that individual's received or provided support.

We predicted end-of-day mood and selfesteem while controlling for previous day mood or self-esteem, daily hassles, and patients' daily symptoms and complaints.

The regression equation was as follows:

$$
\begin{aligned}
& \text { Mijk }=\text { b0 } 0_{i j k}+b 1 M-1_{i j k}+b 2 \text { symptoms }_{i j k}+b 3 \text { hassles }_{i j k}+b 4 \text { role }_{j k}+b 5 R_{i j k}+b 6 P_{i j k}+b 7 R_{i j k} x \\
& \operatorname{Pr}_{i j k}+b 8 \text { role }_{j k} \times R_{i j k}+b 9 \text { role }_{j k} \times \operatorname{Pr}_{i j k}+1 b 10 \text { role }_{j k} \times \operatorname{Pr}_{i j k} \times R_{i j k}+e_{i j k}
\end{aligned}
$$

Note that in this regression equation, the subscripts ijk indicate a variable that varies within persons across time, and the subscripts $j \mathrm{k}$ refer to a time-invariant between-person variable. Mijk, end-of-day mood or self-esteem in person j in couple k on day i; b0ijk, the regression intercept in individual $\mathrm{j}$ in couple $\mathrm{k}$ on day $\mathrm{i}$; M-1ijk, mood or self-esteem on day t -1 in person $\mathrm{j}$ in couple $\mathrm{k}$ on day $\mathrm{i}$; symptomsijk, MS-related symptoms of patient $\mathrm{j}$ in couple $\mathrm{k}$ on day $\mathrm{i}$; hasslesijk, daily hassles in person $\mathrm{j}$ in couple $\mathrm{k}$ on day $\mathrm{i}$; rolejk, indicates whether person $\mathrm{j}$ in couple $\mathrm{k}$ is a patient or partner; Rijk, received support in person $\mathrm{j}$ in couple $\mathrm{k}$ on day i; Prijk, provided support in person $\mathrm{j}$ in couple $\mathrm{k}$ on day i; Prijk xRijk, interaction effect between received and provided support in person $\mathrm{j}$ in couple $\mathrm{k}$ on day $\mathrm{i}$; and eijk, residual effect in individual $\mathrm{j}$ in couple $\mathrm{k}$ on day $\mathrm{i}$.

All predictor variables were grand mean centered (i.e., the overall mean was subtracted from the values of a variable), thus the coefficient b0ijk was the regression intercept for individual $\mathrm{j}$ in couple $\mathrm{k}$ on day $\mathrm{i}$ and represented mood or self-esteem when all variables were at their average level. The role variable (patient or partner) was effect coded, with patients coded as .5 and partners as .5. The significance of the effects was determined with the Wald test: $\mathrm{Z}=$ (estimate)/(standard error of estimate), where $\mathrm{Z}$ referred to the standard normal distribution (Hox, 2002). An alpha level of .05 was used for all statistical tests. 
The dependent variables in our model were end-of-day positive and negative mood and self-esteem. The predictors were entered in the regression equation hierarchically, starting with the covariates (previous day mood or selfesteem, hassles, and patient's symptoms), followed by role (patient or partner), the main effects (received and provided support), and the interaction effect between the main effects, and finally the interaction effects between role and the main effects were entered in the regression equation. Predictors that did not contribute to the dependent variable were removed from the model. However, we included all main effects in the model even when they were not significant because in the presence of a significant interaction, the effect of the interaction variable and the direct effects of the explanatory variables that make up the interaction must be interpreted together as a system (Aiken \& West, 1991). When significant interaction effects were found, regression equations were estimated for persons scoring 1 standard

\section{TABLE 1.}

deviation below and 1 standard deviation above the mean of the interaction variables.

Separate analyses were performed for instrumental support and emotional support and the dependent variables, self-esteem, and positive mood and negative mood.

\section{RESULTS}

\section{Exchange of social support:}

\section{Descriptive analyses}

Aggregated means and standard deviations for received and provided emotional and instrumental support are presented in Table 1. First, Table 1 shows that on average patients reported providing and receiving equal amounts of emotional support. As expected, patients reported providing less instrumental support than they received. Partners reported providing more support (both emotional and instrumental) than they received. Second, when compared to their partners, patients reported receiving more emotional and instrumental support and provided less instrumental support. However, patients and partners did not differ from each other with respect to the amount of emotional support they each said they provided. As expected, these results suggest an imbalance in received and provided instrumental support. That is, both partners agree that patients received more and provided less instrumental support compared to their partners. Both partners did not agree on the imbalance of the exchange of emotional support, however. Although partners reported having received less emotional support than they provided, patients reported having provided as much support as they received.

Finally, we compared the amount of support that one partner reported receiving with the other partner's report of the amount of support provided. The results showed that patients reported providing more emotional support than partners reported receiving. No other differences between the amount of support that one partner reported receiving and the other partner reported providing were found.

\section{Positive mood and social support}

Table 2 presents the final models of the multilevel analyses predicting end-of-day positive mood as a function of receiving and providing emotional support and receiving and providing instrumental support, respectively. The first two steps are the same in both analyses (the b effects differ slightly as a result of the inclusion of other predictors later on in the analyses).

The intercept indicates that the predicted amount of end-of-day positive mood (on a 10-50 scale) was 25.0 for a hypothetical person with an average level of previous day mood, daily hassles, received and provided support, and an average number of symptoms and complaints. 
In the first step, the control variables "previous day mood," "symptoms and complaints," and "hassles" were entered into the regression equations. The number of daily hassles did not significantly contribute to endof- day positive mood and was excluded from further analysis. In the second step, role (patient with MS or partner) was entered into the regression equation. Role did not significantly predict end-of-day positive mood, indicating that patients and partners did not differ in their positive end-of-day mood. In the third step, the main effects of received and provided emotional support and received and provided instrumental support were entered in the regression equation. As Table 2 shows, both received and provided emotional support contributed significantly to end-of-day positive mood, indicating that individuals reported better end-of-day mood when they received and provided more emotional support. In the analysis with instrumental support, only provided support contributed significantly to the regression equation (see Table 2), indicating that individuals reported better end-of-day mood when they provided more instrumental support.

In the fourth step, the interaction between received and provided support was entered in the regression equation to examine whether the effects of receiving support differed as a function of providing support. In both analyses, no interaction effect was found. Finally, the interactions between receiving and providing support on the one hand and role on the other hand were entered in the regression in order to examine whether the effects of received and provided support differed as a function of role (patient or partner). Table 2 shows that in the analysis with emotional support, an interaction between role and support provided was found. As Figure 1 shows, providing more emotional support was related to higher positive mood in patients $(\mathrm{b}=1.34, \mathrm{p}<.01)$ but not in partners $(\mathrm{b}=.05<\mathrm{n}$.s.).

In sum, both patients' and partners' mood benefited from receiving emotional support from their partners and providing instrumental support to their partners. In addition, patients' positive mood benefited from providing emotional support to their partners as well. No support was found for a moderator effect between providing and receiving support over and above the main effects.

\section{Negative mood and social support}

The same analyses were executed to model end-of-day negative mood as a function of receiving and providing emotional and instrumental support. The results are presented in Table 3. The intercept indicates that the predicted amount of end-of-day negative mood (on a $10-50$ scale) in the evening was 14.3 for a hypothetical person with an average level of previous day mood, daily hassles, received and provided support, and an average number of symptoms and complaints. All control variables contributed significantly to end-of-day negative mood in the first step of the analyses. Role (patient or partner) did not significantly predict end-of-day negative

\section{TABLE 2}

\section{FIGURE 1}

mood, indicating that patients and partners did not differ in their end-of-day negative moods. Table 3 further shows that neither receiving nor providing emotional or instrumental support contributed to end-of-day negative mood. The same was true for the interaction between receiving and providing support. In a final step, the interactions between role on the one hand and receiving and providing support on the other hand were significant for emotional support but not for instrumental support. As Figure 2 shows, receiving more emotional support was related to lower levels of negative mood in partners $(b=-.94, \mathrm{p}<.01)$. Among patients, receiving emotional support was unrelated to negative mood $(\mathrm{b}=.09$, n.s.). With respect to providing support, Figure 3 shows that among partners, providing more emotional support was not related to levels of negative mood ( $\mathrm{b}=.36$, n.s.), whereas patients' end-of day mood was less negative as they provided more emotional support $(b=-.87, \mathrm{p}<.01)$. 
In sum, providing emotional support was beneficial for patients, whereas receiving emotional support was unrelated to negative mood.

For partners, the reverse was true: Providing emotional support was not related to negative mood and receiving emotional support was related to less negative mood. Neither receiving nor providing instrumental support was related to negative mood. This was found for patients and for partners. Like the results for positive mood, no interaction effects were found between receiving and providing support.

\section{Self-esteem and social support}

Finally, self-esteem was modeled as a function of receiving and providing emotional and instrumental support. The results are shown in Table 4. The intercept indicated that the predicted amount of self-esteem (on a 1-7 scale) was 5.2 for a hypothetical person with an average level of previous day self-esteem,

\section{[TABLE 3]}

\section{[FIGURE 2]}

daily hassles, received and provided support, and an average number of symptoms and complaints.

All control variables contributed significantly to self-esteem in the first step of the analyses. Role (patient or partner) significantly predicted self-esteem. On average, patients reported lower self-esteem than did their partners (in the analysis with instrumental support, the b weight in the final equation was no longer significant after inclusion of the other predictors). In the third step, emotional support provided and instrumental support provided contributed significantly to the regression. Thus, providing more emotional support and instrumental support was associated with higher self-esteem. In the following step, the interaction between providing and receiving support was significant for instrumental support but not for emotional support.

\section{[FIGURE 3]}

As Figure 4 shows, providing support was not related to self-esteem when low instrumental support was received in return ( $b=04$, n.s.).

In contrast, receiving instrumental support was related to lower self-esteem when little or no instrumental support was provided in return $(b=15, \mathrm{p}<.001)$. Thus, reciprocating instrumental support was beneficial for self-esteem.

In the final step of the analyses, the interaction between role and emotional support provided proved significant. Figure 5 shows that patients reported higher self-esteem when they provided more emotional support to their intimate partner $(b=.28, \mathrm{p}<.001)$. For partners, the relationship between self-esteem and support provision was close to zero $(b=-.04$, n.s.). In sum, with respect to emotional support, the results showed that providing emotional support was related to higher self-esteem among patients but not among their partners. The receipt of emotional support was unrelated to self-esteem. With respect to instrumental support, the predicted interaction between providing and receiving support was significant: Receiving instrumental support was only beneficial for self-esteem when instrumental support was reciprocated. When little or no instrumental support was provided, receiving instrumental support was harmful.

This was true for both patients and partners. ${ }^{2}$ 
Kleiboer, A.M., Kuijer, R.G., Hox, J.J., Schreurs, K.M.G., Bensing, J. Receiving and providing support in couples dealing with multiple sclerosis: a diary study using an equity perspective. Personal Relationships: 2006, 13(4), 485-501

\section{[TABLE 4]}

\section{DISCUSSION}

The present study examined support exchanges among couples in which one partner was diagnosed with MS. First, the imbalance between patients’ and partners' reports of support receipt and provision was examined.

Second, the extent to which reciprocal exchanges of received and provided support were related to end-of-day well-being was examined.

Imbalance in support exchanges As expected, both patients and partners reported an imbalance in the exchange of instrumental support over a 2-week period.

That is, both partners agreed that patients received more and provided less instrumental support compared to the healthy partner. With respect to emotional support, only partners perceived an imbalance in the predicted direction, and in line with the expectations, the imbalance was less pronounced than for instrumental support. Patients did not report an imbalance; they reported providing on average as much emotional support as they received from their partners. Note that we examined individual's subjective perceptions of received and provided support. Apparently, not all the emotional support that was provided

\section{[FIGURE 4]}

\section{[FIGURE 5]}

according to the patient was perceived as such by the partner. Emotional support is less visible compared to instrumental support and is therefore more difficult to notice. Partners have more distractions in their lives than do patients. Not only do partners provide much practical help and care, the majority of them in the present study were employed outside the home. It is possible that partners are less aware of the emotional support that is provided to them because they have so many other things to do. Another possibility is that due to their own needs, patients may be less attuned to the needs of their partners; therefore, patients may not provide as much emotional support as they report.

\section{Reciprocal exchanges of support}

In line with equity theory, receiving instrumental help was associated with lower levels of self-esteem when it was not reciprocated, both for patients and partners. Apparently, receiving instrumental support without providing instrumental support in return (overbenefit in equity terms) has negative consequences for the recipient's self-esteem. For patients, the inability to reciprocate instrumental help may emphasize their status as an impaired person and may stress their dependency (DiMatteo \& Hays, 1981; Liang et al., 2001). For partners, not being able to reciprocate instrumental help may threaten their competence as a caregiver. Ybema et al. (2002) found that partners of patients with cancer or MS who felt that they invested too little in their relationships in terms of help and support experienced lower levels of personal accomplishment about their caregiving role. Reciprocity of instrumental help was not important with respect to end-of-day mood. One explanation may be that selfesteem is more susceptible to reciprocal exchanges of instrumental support than mood.

Self-esteem and mood are believed to be different concepts. However, it is not well-known if and to what extent they are affected by daily occurrences in a different way. A series of experiments by Heatherton and Polivy (1991) showed that mild ego distress was related to a change in self-esteem but not to a change in mood. It may be that when patients or partners were not able to return instrumental help on a certain day, they evaluated themselves less positively, however, it did not affect their moods. In contrast with equity theory, underbenefit (providing much instrumental support without receiving in return) was not related to selfesteem. 
Kleiboer, A.M., Kuijer, R.G., Hox, J.J., Schreurs, K.M.G., Bensing, J. Receiving and providing support in couples dealing with multiple sclerosis: a diary study using an equity perspective. Personal Relationships: 2006, 13(4), 485-501

In addition, providing instrumental support was related to positive mood among both patients and their partners regardless of whether support was reciprocated. Apparently, being able to provide practical assistance may be rewarding in itself both for patients and partners (cf. Williamson\&Clark, 1989; Nijboer et al., 1998). Also in contrast with our expectations, no support was found for the importance of reciprocating emotional support.

Interestingly, the effects of received and provided emotional support were uniquely related to the patient or partner role. Patients reported better well-being when they provided higher levels of emotional support, whereas partners reported better mood when they received more emotional support. Providing emotional support may be particularly important for patients because it gives them the opportunity to show appreciation for the help and care they receive from their partners (Thompson \& Pitts, 1992).

For partners, receiving emotional support may be especially valuable because it communicates appreciation and love.

Apart from the relation between instrumental support and self-esteem, the present study did not provide support for the idea that support needs to be reciprocated immediately to be beneficial. Most studies that have showed the negative effects of inequity among couples dealing with chronic illness used global appraisals of each partners' contributions and rewards to the relationship (e.g., Kuijer et al., 2001; Thompson et al., 1995; Ybema, et al., 2001). In this study, we asked participants to report the amount of support they had received or provided at the end-of-day, we did not ask them whether they felt equitably treated or not. As was mentioned before, this means that participants in inequitable situations may not have actually felt inequitably treated. Several researchers have argued that in intimate relationships a need-based rule is the typical rule and that equity is less important (e.g., Clark \& Mills, 1979). The present study suggests that at least on a day-to-day basis, prompt repayment in kind after receiving emotional support is not necessary in the context of illness. The results regarding emotional support are not in line with findings from Gleason et al. (2003) who found that reciprocity in emotional support transactions on a given day was associated with better end-of-day mood on that day among healthy couples. It is possible that in the context of illness, the exchange of emotional interactions has a different meaning than when both partners are healthy.

The current study showed that it is important to distinguish between instrumental and emotional support. Most studies looking at the effects of enacted support either examine only emotional or instrumental support (e.g., Gleason et al., 2003; Newsom \& Schulz, 1998) or do not distinguish between the two (e.g., Liang et al., 2001). This may contribute to the inconsistent effects of enacted support on well-being simply because different types of support may have different effects on wellbeing.

A disadvantage of separately analyzing the effects of emotional and instrumental support, however, is that we were unable to examine whether, for example, instrumental support could be reciprocated by providing emotional support. Support expectations may change in the context of chronic illness. For example, patients may expect to receive more instrumental support. Therefore, providing emotional support may be one way to compensate for the instrumental help they receive.

Partners on the other hand may expect to receive less instrumental support. For them, receiving emotional support from their partners may be one way to compensate for the instrumental help they provide. Future research is needed to examine this issue.

\section{Limitations}

A first limitation of the present study is that the majority of our sample consisted of couples with a female patient and a male partner. It is possible that the differences between patients and partners that we found may reflect gender differences. There is evidence that women and men attach different meanings to supportive behaviors and that women are generally more sensitive to support transactions than are men (Acitelli \& Antonucci, 1994). We did explore gender differences (see note 2) and few emerged. However, the results of these analyses are 
Kleiboer, A.M., Kuijer, R.G., Hox, J.J., Schreurs, K.M.G., Bensing, J. Receiving and providing support in couples dealing with multiple sclerosis: a diary study using an equity perspective. Personal Relationships: 2006, 13(4), 485-501

highly tentative because the gender imbalance in our sample did not allow us to examine gender differences in a reliable way.

We did not find support for the idea that women were more sensitive to supportive behaviors than men. In contrast, only male patients benefited from providing emotional support with respect to their positive mood.

Further, only female partners reported higher levels of self-esteem on days that they provided more instrumental support. The latter is in line with a study by Hagedoorn, Sanderman, Buunk, and Wobbes (2002) that showed that women's distress was related to their feelings of competence as a caregiver but not to men's. Future research is needed to examine this issue more thoroughly.

Second, the diary method that we used in this study provides the opportunity to examine the effects of support processes over time.

However, the nonexperimental nature of the data precludes causal statements. Further, recordings of support and well-being have been assessed on the same moment (end-ofday). It is possible that patients or partners who were in a better mood or had higher self-esteem were inclined to report more or less received or provided support, which can be considered a limitation of the present study.

We controlled for important confounding variables, that is, previous day well-being, daily hassles, and MS-related complaints. Thus, we protected to some extent against the problem of well-being simply predicting perceptions of spousal exchanges. However, other unknown factors could have influenced both well-being and support exchanges. Furthermore, there may be complex patterns between support received and provided that exceed over days or even months and are cumulative. For example, one-sided received support on Day 1 may be compensated by providing support on Day 2. More research is needed to examine these processes.

Additionally, we did not investigate whether the effects of giving and receiving support were dependent on the person or the couple. Although we did find evidence that the effects of support exchanges varied as a function of between-person and between-couple differences, we did not examine this any further because it was beyond the scope of this study. Variance explained by between-person or couple differences means that certain aspects of the couple or the individual moderate the effects of receiving and providing support.

The effects of spousal exchanges may, for example, depend on the patient's physical disability. For example, the costs and benefits of receiving and providing support may be different for a patient who is seriously disabled compared to a patient who is less disabled (Wright \& Aquilino, 1998). Further, when a patient is seriously disabled and needs lots of help, equity may no longer be important and needs may prevail over equity rules (Kuijer et al., 2001).

Finally, the fact that both patients with MS and their partners had to complete diaries may have led to an underrepresentation of distressed couples. It is possible that distressed couples were less willing to participate in a study like this as a couple. Additionally, our sample varied widely with respect to age and relationship length; however, on average, the couples had been together for a very long time. The fact that these couples are still together after such a long time suggests that they somehow managed to deal with the MS in their relationship, successfully.

\section{Conclusions}

To conclude, this study showed that daily support exchanges in couples facing chronic illness may become imbalanced when one partner is diagnosed with MS, most pronounced in instrumental support. Our results indicated that the consequences of support exchanges were for a large part dependent on the type of support and the patient or partner role. Our findings have important implications.

Most studies and interventions on support in chronic illness focus on the patient as the support recipient and the partner as the support provider. However, this study showed the 
Kleiboer, A.M., Kuijer, R.G., Hox, J.J., Schreurs, K.M.G., Bensing, J. Receiving and providing support in couples dealing with multiple sclerosis: a diary study using an equity perspective. Personal Relationships: 2006, 13(4), 485-501

importance of providing support to the partner for the patient's well-being and receiving emotional support from the ill partner for the partner's well-being. Future interventions should not only concentrate on the patient's needs for support, however, they should also encourage patients to explore their opportunities as a supportive partner. Additionally, for partners, it is important that more attention will be given to their potential role as support recipients.

\section{REFERENCES}

Acitelli, L. K., \& Antonucci, T. C. (1994). Gender differences in the link between marital support and satisfaction in older couples. Journal of Personality and Social Psychology, 6(4), 688-698.

Aiken, L. S., \& West, S. G. (1991). Multiple regression: Testing and interpreting interactions. Newbury Park, CA: Sage.

Antonucci, T. C., \& Jackson, J. S. (1990). The role of reciprocity in social support. In B. R. Sarason, I. G.

Sarason, \& G. R. Pierce (Eds.), Social support: An interactional view (pp. 173-198). New York: John Wiley.

Bensing, J. M., Schreurs, K. M. G., De Ridder, D. T. D., \& Hulsman, R. L. (2002). Adaptive tasks in multiple sclerosis: Development of an instrument to identify the focus of patients' coping efforts. Psychology and Health, 17(4), 475-478.

Burman, B., \& Margolin, G. (1992). Analysis of the association between marital relationships and health problems: An interactional perspective. Psychological Bulletin, 112(1), 39-63.

Butler, A. C., Hokanson, J. E., \& Flynn, H. A. (1994).

A comparison of self-esteem lability and low trait self-esteem as vulnerability factors for depression.

Journal of Personality and Social Psychology, 66(1), 166-177.

Bolger, N., Foster, M., Vinokur, A. D., \& Ng, R. (1996).

Close relationships and adjustments to a life crisis: The case of breast cancer. Journal of Personality and Social Psychology, 70(2), 283-294.

Bolger, N., Zuckerman, A., \& Kessler, R. C. (2000). Invisible support and adjustment to stress. Journal of Personality and Social Psychology, 79(6), 953-961.

Brown, S. L., Nesse, R. M., Vinokur, A. D., \& Smith, D.

M. (2003). Providing social support may be more beneficial than receiving it: Results from a prospective study of mortality. Psychological Science, 14(4), 320-327.

Buunk, B. P., \& Schaufeli, W. B. (1999). Reciprocity in interpersonal relationships: An evolutionary perspective on its importance for health and well-being. In W. Stroebe \& M. Hewstone (Eds.), European review of social psychology (Vol. 10). Chichester: Wiley.

Clark, M. S., \& Mills, J. (1979). Interpersonal attraction in exchange and communal relationships. Journal of Personality and Social Psychology, 37(1), 12-24.

Cutrona, C. E. (1996). Social support in couples: Marriage as a resource in times of stress. Thousand Oaks, CA: Sage.

DeLongis, A., Folkman, S., \& Lazarus, R. S. (1988). The impact of daily stress on health and mood: Psychological and social resources as mediators. Journal of Personality and Social Psychology, 54(3), 486-495.

DiMatteo, M. R., \& Hays, R. (1981). Social support and serious illness. In B. H. Gottlieb (Eds.), Social networks and social support (pp. 117-148). Beverly Hills, CA: Sage.

Dunkel-Schetter, C., \& Bennett, T. L. (1990). Differentiating the cognitive and behavioral aspects of social support. In I. G. Sarason\& B. R. Sarason (Eds.), Social support: An interactional view (pp. 267-296). Oxford, England: John Wiley.

Fisher, J. D., Nadler, A., \& Whitcher-Alagna, S. (1982).

Recipient reactions to aid. Psychological Bulletin, 91(1), 27-54.

Gleason, M. E. J., lida, M., Bolger, N., \& Shrout, P. E.

(2003). Daily supportive equity in close relationships.

Personality and Social Psychology Bulletin, 29(8), 1036-1045.

Grote, N. K., \& Clark, M. S. (2001). Perceiving unfairness in the family: Cause or consequence of marital distress? Journal of Personality and Social Psychology, 80(2), 281-293. 
Kleiboer, A.M., Kuijer, R.G., Hox, J.J., Schreurs, K.M.G., Bensing, J. Receiving and providing support in couples dealing with multiple sclerosis: a diary study using an equity perspective. Personal Relationships: 2006, 13(4), 485-501

Hagedoorn, M., Sanderman, R., Buunk, B. P., \& Wobbes, T. (2002). Failing in spousal caregiving: The "identity- relevant stress" hypothesis to explain sex differences in caregiver distress. British Journal of Health Psychology, 7(4), 481-494.

Heatherton, T. F., \& Polivy, J. (1991). Development and validation of a scale for measuring state self-esteem.

Journal of Personality and Social Psychology, 60(6), 895-910.

Helgeson, V. S., \& Cohen, S. (1996). Social support and adjustment to cancer: Reconciling descriptive, correlational, and intervention research. Health Psychology, 15(2), 135-148.

Holm, S. (1979). A simple sequentially rejective multiple test procedure. Scandinavian Journal of Statistics, 6, 65-70.

Hox, J. J. (2002). Multilevel analysis: Techniques and applications. Mahwah, NJ: Erlbaum. Knight, R. G., Devereux, R. C., \& Godfrey, H. P. D.

(1997). Psychosocial consequences of caring for a spouse with multiple sclerosis. Journal of Clinical and Experimental Neuropsychology, 19(1), 7-19.

Kuijer, R. G., Buunk, B. P., \& Ybema, J. F. (2001). Are equity concerns important in the intimate relationship when one partner of a couple has cancer? Social Psychology Quarterly, 64(3), 267-282.

Liang, J., Krause, N. M., \& Bennett, J. M. (2001). Social exchange and well-being: Is giving better than receiving? Psychology and Aging, 16(3), 511-523.

Lindorff, M. (2000). Is it better to perceive than receive? Social support, stress and strain for managers. Psychology, Health and Medicine, 5(3), 271-286.

Lublin, F. D., \& Reingold, S. C. (1996). Defining the clinical course of multiple sclerosis: Results of an international survey. National Multiple Sclerosis Society (USA) Advisory Committee on Clinical Trials of New Agents in Multiple Sclerosis. Neurology, 46, 907-911.

Manne, S. L., \& Zautra, A. J. (1989). Spouse criticism and support: Their association with coping and psychological adjustment among women with rheumatoid arthritis.

Journal of Personality and Social Psychology, 56(4), 608-617.

Martire, L. M., \& Schulz, R. (2001). Informal caregiving to older adults: Health effects of providing and receiving care. In A. Baum, T. A. Revenson, \& J. E. Singer (Eds.), Handbook of health psychology (pp. 477-491).

Mahwah, NJ: Erlbaum.

Mohr, D. C., \& Dick, L. P. (1998). Multiple sclerosis. In S. J. Knight \& P. M. Camic (Eds.), Clinical handbook of health psychology: A practical guide to effective interventions (pp. 313-348). Ashland, OH: Hogrefe \& Huber.

Newsom, J. T., \& Schulz, R. (1998). Caregiving from the recipient's perspective: Negative reactions to being helped. Health Psychology, 17(2), 172-181.

Nijboer, C., Tempelaar, R., Sanderman, R., Triemstra, M., Spruijt, R. J., \& Van den Bos, G.

A. M. (1998). Cancer and caregiving: The impact on the caregiver's health.

Psycho-Oncology, 7, 3-13.

Pakenham, K. I. (1998). Couple coping and adjustment to multiple sclerosis in care receivercarer dyads. Family Relations: Interdisciplinary Journal of Applied Family Studies, 47(3), 269-277.

Rasbash, J., Browne, W., Goldstein, H., \& Yang, M.

(2000). A user's guide to MLwiN (2nd ed.). London: Institute of Education.

Riemsma, R. P., Taal, E., Wiegman, O., Rasker, J. J., Bruyn, G. A. W., \& van Paassen, H. C. (2000). Problematic and positive support in relation to depression in people with rheumatoid arthritis. Journal of Health Psychology, 5(2), 221-230.

Robins, R. W., Hendin, H. M., \& Trzesniewski, K. H.

(2001). Measuring global self-esteem: Construct validation of a single-item measure and the Rosenberg Self-Esteem Scale. Personality and Social Psychology Bulletin, 27(2), 151161.

Rosenberg, M. (1965). Society and the adolescent selfimage.

Princeton, NJ: Princeton University Press.

Rusbult, C. E., \& Van Lange, P. A. M. (1996). Interdependence processes. In A. W. E. Kruglanski \& E. T.

Higgins (Eds.), Social psychology: Handbook of basic principles (pp. 564-596). New York: Guilford.

Sarason, B. R., Sarason, I. G., \& Gurung, R. A. R. (2001). 
Close personal relationships and health outcomes: A key to the role of social support. In B. R. Sarason \& S. E. Duck (Ed.), Personal relationships: Implications for clinical and community psychology (pp. 547-573).

New York: John Wiley.

Silverstein, M., Chen, X., \& Heller, K. (1996). Too much of a good thing? Intergenerational social support and the psychological well-being of older parents. Journal of Marriage and the Family, 58(4), 970-982.

Sprecher, S. (2001). Equity and social exchange in dating couples: Associations with satisfaction, commitment and stability. Journal of Marriage and the Family, 63, 599-613.

Thompson, S. C., Medvene, L. J., \& Freedman, D. (1995).

Caregiving in the close relationships of cardiac patients: Exchange, power, and attributional perspectives on caregiver resentment. Personal Relationships, 2, 125-142.

Thompson, S. C., \& Pitts, J. S. (1992). In sickness and in health: Chronic illness, marriage, and spousal caregiving.

In S. Oskamp \& S. Spacapan (Eds.), Helping and being helped: Naturalistic studies (pp. 115-151).

Thousand Oaks, CA: Sage.

Walster, E., Walster, G. W., \& Berscheid, E. (1978).

Equity: Theory and research. Boston: Allyn and Bacon.

Watson, D., Clark, L. A., \& Tellegen, A. (1988).

Development and validation of brief measures of positive and negative affect: The PANAS scales. Journal of Personality and Social Psychology, 54(6), 1063-1070.

Williamson, G. M., \& Clark, M. S. (1989). Providing help and desired relationship type as determinants of changes in moods and self-evaluations. Journal of Personality and Social Psychology, 56(5), 722-734.

Wright, D. L., \& Aquilino, W. S. (1998). Influence of emotional support exchange in marriage on caregiving wives' burden and marital satisfaction. Family Relations: Interdisciplinary Journal of Applied Family Studies, 47(2), 195-204.

Ybema, J. F., Kuijer, R. G., Buunk, B. P., DeJong, G. M., \& Sanderman, R. (2001). Depression and perceptions of inequity among couples facing cancer. Personality and Social Psychology Bulletin, 27(1), 3-13.

Ybema, J. F., Kuijer, R. G., Hagedoorn, M., \& Buunk, B. P. (2002). Caregiver burnout among intimate partners of patients with a severe illness: An equity perspective. Personal Relationships, 9(1), 73-88.

Zwanikken, C. P. (1997). Multiple Sclerose: Epidemiologie en kwaliteit van leven (Multiple sclerosis: Epidemiology and quality of life). Groningen, the Netherlands: Groningen University. 


\section{TABLES AND FiguRES}

Table 1. Average amount of received and provided emotional and instrumental support in multiple sclerosis patients and their partners across the 14-day period

\begin{tabular}{lcc}
\hline \hline & Received & Given \\
\hline Emotional support & \\
Patients & $1.83(.75)^{\text {axp }}$ & $1.87(.72)^{\text {axq }}$ \\
Partners & $1.54(.79)^{\text {ayp }}$ & $1.69(.71)^{\text {bxp }}$ \\
Instrumental support & \\
Patients & $1.78(.83)^{\text {axp }}$ & $1.22(.82)^{\text {bxp }}$ \\
Partners & $1.06(.80)^{\text {ayp }}$ & $1.73(.89)^{\text {byp }}$ \\
\hline \hline
\end{tabular}

Note. Values are means $(S D)$. Means with a different superscript in a row (letters a and b) differ significantly from each other at least at $p<.05$. Means with a different superscript in a column (letters $\mathrm{x}$ and $\mathrm{y}$ ) differ significantly from each other at least at $p<.05$. Means with a different superscript in a diagonal (letters $\mathrm{p}$ and $\mathrm{q}$ ) differ significantly from each other at least at $p<.05$. BonferroniHolm step-down procedure was used to adjust for multiple comparisons (Holm, 1979).

Table 2. Effects of emotional and practical support received from and provided to the partner on end-of-day positive mood

\begin{tabular}{|c|c|c|c|c|c|c|c|c|}
\hline & \multicolumn{4}{|c|}{ Emotional support } & \multicolumn{4}{|c|}{ Practical support } \\
\hline & Effect & $S E$ & $Z$ & $p$ value & Effect & $S E$ & $Z$ & $p$ value \\
\hline Intercept & $25.00 * * *$ & .53 & 47.26 & .00 & $24.91 * * *$ & .56 & 44.48 & .00 \\
\hline Previous day mood & $.16^{* * *}$ & .03 & 6.08 & .00 & $.16^{* * *}$ & .03 & 6.00 & .00 \\
\hline Symptoms/complaints & $-.53 * * *$ & .10 & 5.28 & .00 & $-.59 * * *$ & .10 & 5.79 & .00 \\
\hline Role (patient/partner) & .99 & .70 & 1.43 & .15 & .38 & .70 & .55 & .59 \\
\hline Support receipt & $.97 * *$ & .33 & 2.93 & .00 & .15 & .17 & .84 & .40 \\
\hline Support given & $.81^{*}$ & .34 & 2.35 & .02 & $.76^{* * *}$ & .17 & 4.37 & .00 \\
\hline Receipt $\times$ Given & -.19 & .24 & .79 & .43 & .14 & .13 & 1.06 & .29 \\
\hline Role $\times$ Received & .31 & .65 & .47 & .64 & .03 & .36 & .09 & .93 \\
\hline Role $\times$ Given & $-1.38^{*}$ & .68 & 2.02 & .04 & -.16 & .37 & .43 & .67 \\
\hline
\end{tabular}

$* p<.05 . * * p<.01 . * * * p<.001$. 
Kleiboer, A.M., Kuijer, R.G., Hox, J.J., Schreurs, K.M.G., Bensing, J. Receiving and providing support in couples dealing with multiple sclerosis: a diary study using an equity perspective.

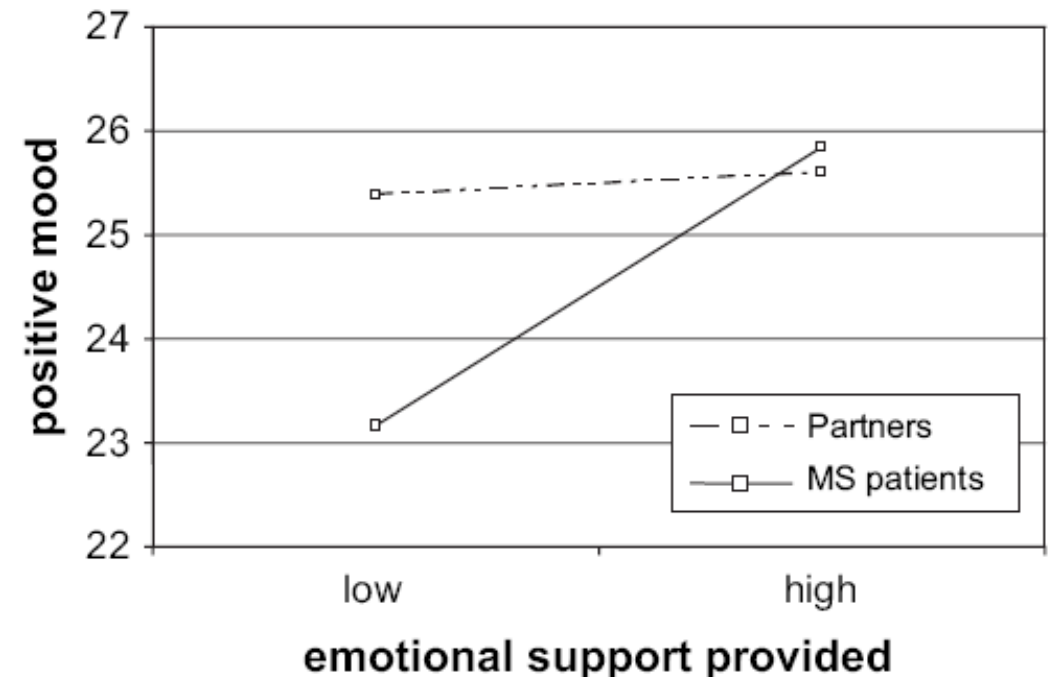

Figure 1. Positive mood as a function of emotional support provided for patients with multiple sclerosis and their partners.

Table 3. Effects of emotional and practical support received from and provided to the partner on end-of-day negative mood

\begin{tabular}{|c|c|c|c|c|c|c|c|c|}
\hline & \multicolumn{4}{|c|}{ Emotional support } & \multicolumn{4}{|c|}{ Practical support } \\
\hline & Effect & $S E$ & $Z$ & $p$ value & Effect & $S E$ & $Z$ & $p$ value \\
\hline Intercept & $14.28 * * *$ & .30 & 47.58 & .00 & $14.28 * * *$ & .29 & 49.76 & .00 \\
\hline Previous day mood & $.22 * * *$ & .03 & 8.60 & .00 & $.22 * * *$ & .03 & 8.64 & .00 \\
\hline Symptoms/complaints & $.52 * * *$ & .07 & 7.86 & .00 & $.53 * * *$ & .07 & 7.96 & .00 \\
\hline Hassles & $.44 * * *$ & .05 & 9.87 & .00 & $.46^{* * * *}$ & .05 & 10.27 & .00 \\
\hline Role (patient/partner) & -.29 & .49 & .61 & .55 & -.07 & .49 & .14 & .89 \\
\hline Support receipt & -.37 & .22 & 1.65 & .10 & .02 & .12 & .13 & .90 \\
\hline Support given & -.29 & .24 & 1.22 & .22 & -.10 & .12 & .86 & .39 \\
\hline Receipt $\times$ Given & -.04 & .16 & .22 & .82 & -.07 & .08 & .80 & .43 \\
\hline Role $\times$ Received & $-1.01 *$ & .45 & 2.26 & .02 & .03 & .33 & .08 & .94 \\
\hline Role $\times$ Given & $1.38 * *$ & .46 & 2.97 & .00 & .09 & .25 & .36 & .72 \\
\hline
\end{tabular}

$* p<.05 .{ }^{* *} p<.01 .{ }^{* * *} p<.001$. 
Kleiboer, A.M., Kuijer, R.G., Hox, J.J., Schreurs, K.M.G., Bensing, J. Receiving and providing support in couples dealing with multiple sclerosis: a diary study using an equity perspective.

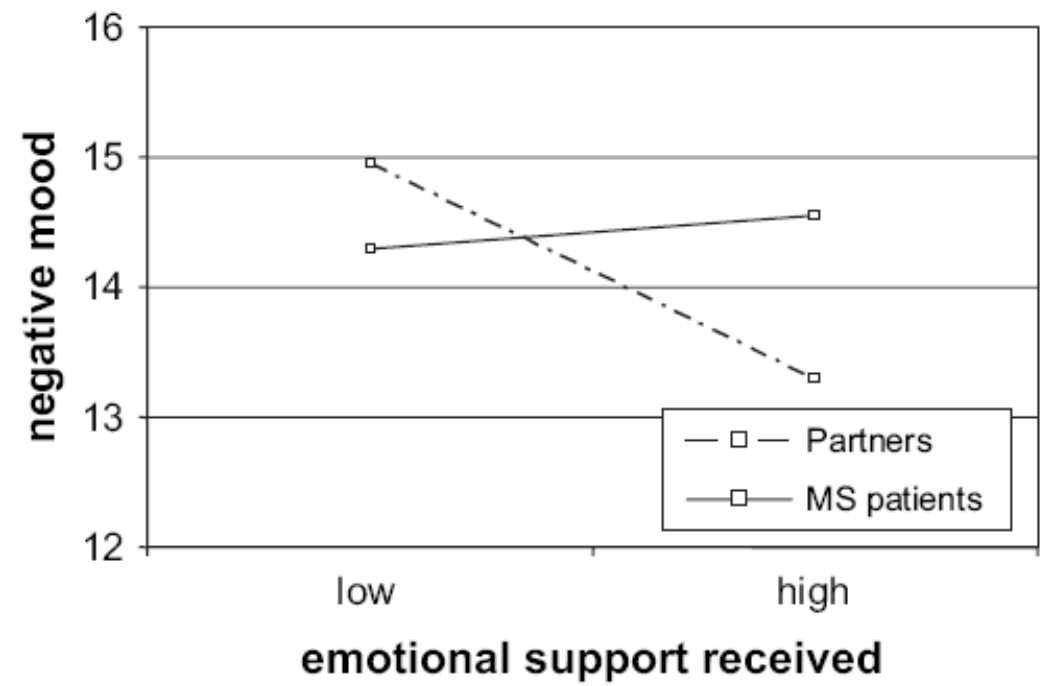

Figure 2. Negative mood as a function of emotional support received for patients with multiple sclerosis and their partners.

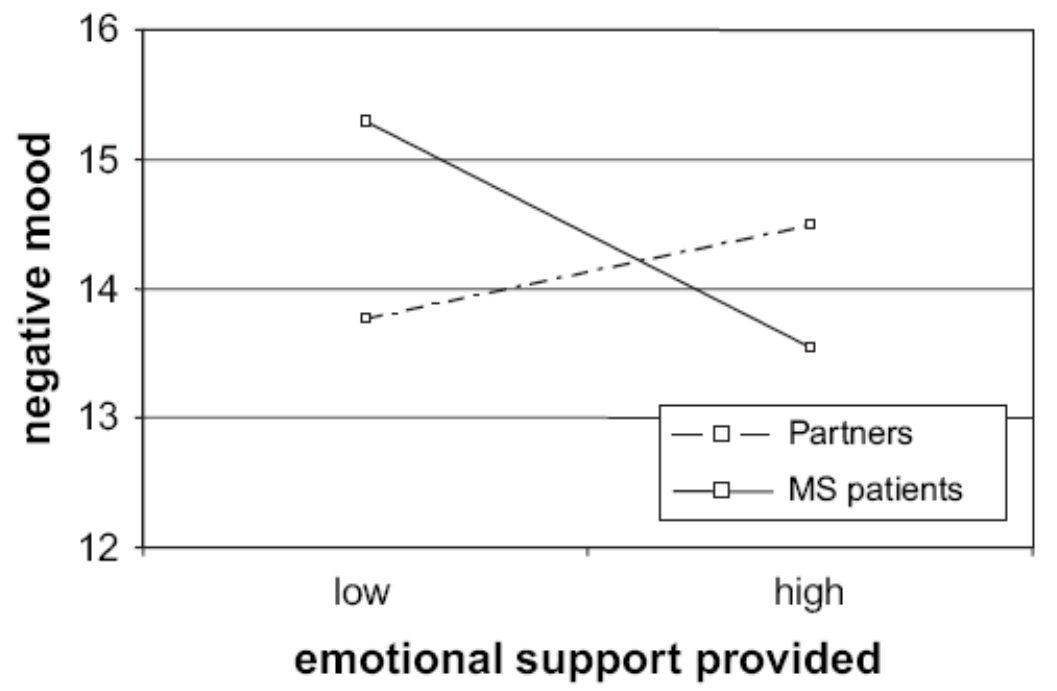

Figure 3. Negative mood as a function of emotional support provided for patients with multiple sclerosis and their partners. 
Kleiboer, A.M., Kuijer, R.G., Hox, J.J., Schreurs, K.M.G., Bensing, J. Receiving and providing support in couples dealing with multiple sclerosis: a diary study using an equity perspective. Personal Relationships: 2006, 13(4), 485-501

Table 4. Effects of emotional and practical support received from and provided to the partner on self-esteem

\begin{tabular}{|c|c|c|c|c|c|c|c|c|}
\hline & \multicolumn{4}{|c|}{ Emotional support } & \multicolumn{4}{|c|}{ Practical support } \\
\hline & Effect & $S E$ & $Z$ & $p$ value & Effect & $S E$ & $Z$ & $p$ value \\
\hline Intercept & $5.18^{* * *}$ & .07 & 70.00 & .00 & $5.18 * * *$ & .08 & 68.16 & .00 \\
\hline Previous day self-esteem & $.15^{* * *} *$ & .03 & 5.89 & .00 & $.15^{\text {*** }}$ & .03 & 5.89 & .00 \\
\hline Symptoms/complaints & $-.09 * * *$ & .02 & 5.38 & .00 & $-.09 * * *$ & .02 & 5.69 & .00 \\
\hline Hassles & $-.05 * * *$ & .01 & 4.46 & .00 & $-.06^{* * *}$ & .01 & 5.09 & .00 \\
\hline Role (patient/partner) & $.19 *$ & .10 & 1.93 & .03 & .10 & .10 & 1.00 & .16 \\
\hline Support receipt & .06 & .05 & 1.13 & .13 & -.01 & .03 & .46 & .32 \\
\hline Support given & $.13^{* *}$ & .06 & 2.39 & .01 & $.10^{* * *} *$ & .03 & 3.39 & .00 \\
\hline Receipt $\times$ Given & -.00 & .04 & .08 & .47 & $.04 *$ & .02 & 2.00 & .02 \\
\hline Role $\times$ Received & .03 & .11 & .28 & .39 & -.02 & .06 & .40 & .35 \\
\hline Role $\times$ Given & $-.32 * *$ & .11 & 2.89 & .00 & -.07 & .06 & 1.17 & .12 \\
\hline
\end{tabular}

${ }^{*} p<.05 . * * p<.01 . * * * p<.001$.

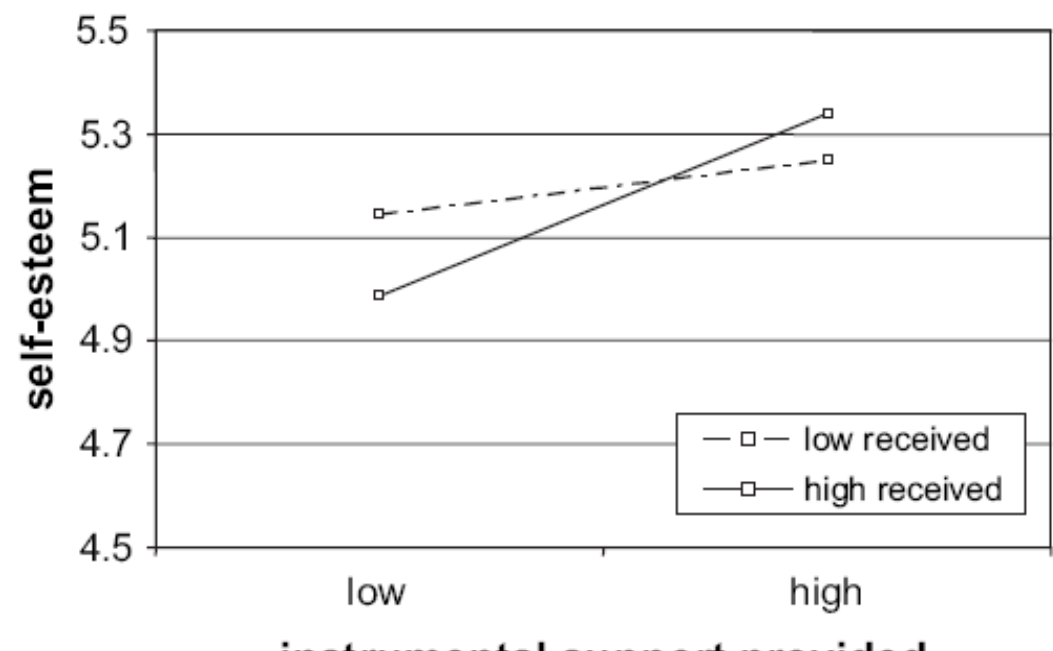

instrumental support provided

Figure 4. Self-esteem as a function of instrumental support provided to the partner and received from the partner. 
Kleiboer, A.M., Kuijer, R.G., Hox, J.J., Schreurs, K.M.G., Bensing, J. Receiving and providing support in couples dealing with multiple sclerosis: a diary study using an equity perspective. Personal Relationships: 2006, 13(4), 485-501

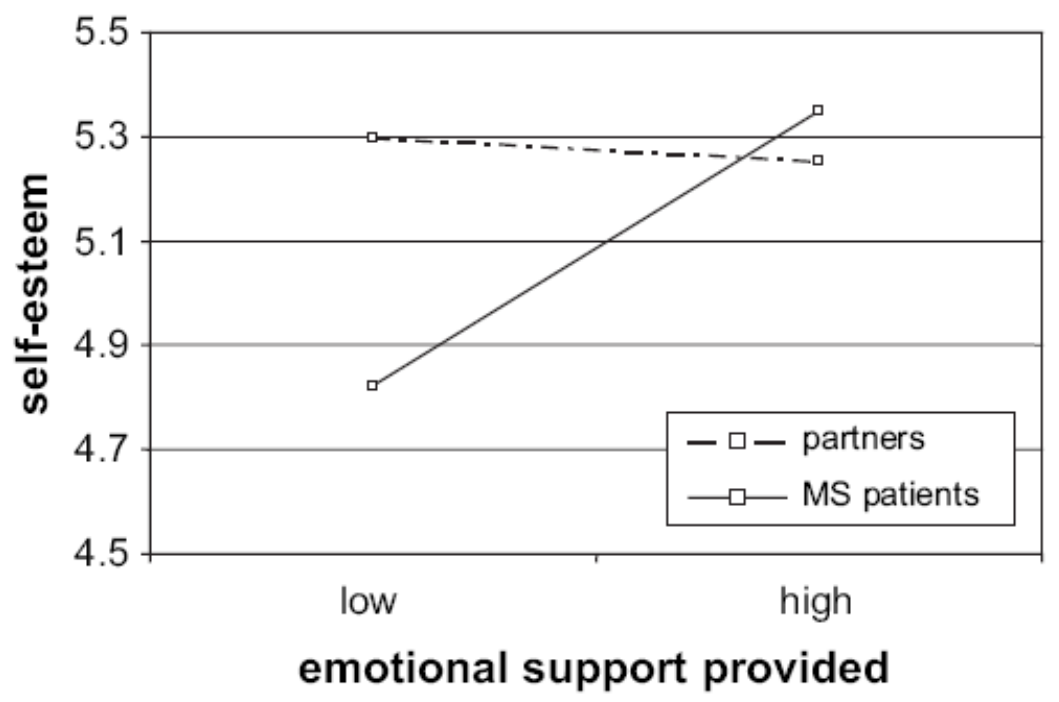

Figure 5. Self-esteem as a function of emotional support provided for patients with multiple sclerosis and their partners. 